\title{
A critique of international indicators of sexual risk behaviour
}

\section{E Slaymaker}

Correspondence to: Ms E Slaymaker, Centre for Population Studies, London School of Hygiene and Tropical Medicine, 49-51 Bedford Square, London WCIB 3DP, UK; emma.slaymaker@ Ishtm.ac.uk

Accepted for publication 11 August 2004

\begin{abstract}
Objectives: To investigate whether the indicators of sexual risk behaviour, defined by UNAIDS for use among members of general populations, have been found as risk factors, to examine how information on sexual behaviour is collected and summarised in order to calculate the indicators, and to look for possible sources of error in the data and in interpretation of those indicators.

Methods: The literature on risk factors for HIV infection was reviewed. Indicators were calculated for countries where data were available for two or more points in time.

Results: Indicators of sexual behaviour describe behaviours that are relevant to HIV risk and that are amenable to change. These behaviours do not correspond closely to the individual risk factors for HIV infection that have been identified in observational studies.

Conclusions: Although potential errors of both measurement and interpretation exist, most of the indicators currently defined can fulfil their purpose, providing they are used with caution. Many of the indicators should not be interpreted in isolation but need supporting information to make sense of trends or differences between groups. Much of this information is provided by other indicators. The source of the data used to calculate the indicator is potentially important and should always be provided with indicator estimates. Some estimate of the accuracy of the estimate, either by means of confidence intervals or the number of respondents, should be given.
\end{abstract}

$\mathrm{T}$ he chances of acquiring HIV infection can be reduced. Patterns of sexual behaviour determine the probability of exposure to an infected partner and can be modified to lessen that chance. Sexual transmission can be reduced by about $80 \%$ with the consistent and correct use of condoms. ${ }^{1}$ Parenteral transmission through contaminated injections or blood products can be prevented by screening and proper sterilisation procedures. Vertical transmission can be reduced with the correct and timely use of antiretroviral drugs. ${ }^{2}$ People in many parts of the world, however, do not know how to protect themselves from HIV infection. ${ }^{3}$ Others are unable or unwilling to act on their knowledge because of personal, cultural, geographical, and economic barriers. ${ }^{4}$

HIV prevention programmes aim to increase knowledge about HIV/AIDS and remove barriers to the adoption of preventive behaviours. Sexual transmission is the predominant mode of HIV transmission in most parts of the world and modification of one or more aspects of an individual's sexual behaviour-towards "safer" behaviours-is a key component of most programmes. The success of prevention programmes is ultimately judged by the impact on the number of new HIV infections, but this is difficult to measure and so the prevalence of HIV infections is often used instead. Prevalence is slow to respond to change. It is, therefore, important to measure behaviour itself because evidence of changes in behaviour should be apparent before HIV prevalence changes.

Sexual behaviour has several dimensions (for example, number of partners, relationship to partner, frequency of sex, condom use) and these interact to produce a different risk profile for each person. In order to track changes in sexual behaviour the key elements must be distilled from selfreported data and effectively summarised to form indicators. If the measurement of indicators is standardised and then estimated at successive points in time, changes in behaviour will be evident as trends in the value of the indicator over time.
Good indicators describe behaviours that are relevant to HIV infection and amenable to change through policy and programme initiatives. Ideally, they should be defined in such a way that they are specific, measurable, reliable, valid and simple to interpret. Because indicators of sexual behaviour are used primarily to track trends they should be relevant over a long period of time. If used at the international level they must be relevant in different populations.

Standard indicators of sexual behaviour were first defined by the Global Programme on AIDS (GPA). ${ }^{5}$ They were subsequently refined by UNAIDS $^{6}$ and additional sets have been compiled by organisations such Family Health International ${ }^{7}$ and Save the Children. ${ }^{8}$ With the implementation of the UN General Assembly Special Session on HIV/ AIDS (UNGASS) declaration by 189 countries in 2001, the use of indicators to monitor sexual behaviour has been firmly set at the centre of global HIV/AIDS prevention efforts. ${ }^{9}$

The main purpose of this paper is to present a critical analysis of key indicators and make suggestions for improved measurement, use, and interpretation. The paper starts with a overview of the indicators currently used. The definition of each indicator is then compared with ways in which risk factors have been measured in specific studies.

\section{CURRENT INDICATORS}

Standard measures of sexual behaviour are used by many organisations for the monitoring and evaluation of programmes and interventions and to target resources and prevention efforts. Many of these organisations use their own indicators, defined to suit their particular purposes.

The 1994 GPA prevention indicators included two on sexual behaviour. ${ }^{5}$ Subsequently many other compendia have been published by different organisations. The set currently

Abbreviations: CSW, commercial sex worker; GPA, Global Programme on AIDS; UNGASS, UN General Assembly Special Session. 
most widely used are those from UNAIDS, the successor to the GPA. This guide retains some indicators from the GPA guide and defines many others. UNAIDS classifies indicators as core and additional. Core indicators are those which are essential to describe the risk profile of a population; additional indicators help in interpreting the core indicators and/or provide extra information about risk behaviour.

The current UNAIDS indicator definitions are given in table 1. Two core indicators of sexual behaviour are recommended for monitoring and evaluation of national AIDS control programmes among adults in the general population in all countries (UN1 and UN2). ${ }^{6}$ For concentrated epidemics four core indicators are recommended in addition to these (UN3, UN4, UN6, and UN7). Five core indicators are recommended to describe the behaviour of young people in countries with generalised epidemics (UNyl to UNy5), although these were under revision at the time of writing this paper. The second core indicator for all adults (UN2) was selected as the main behavioural indicator with which to assess progress towards the UNGASS goals.

Indicators have standard definitions but not target values or ranges. Although each indicator has a theoretical relation to HIV risk, few of these relations have been quantified. Risk is determined by the interaction between the different aspects of behaviour and HIV prevalence. While overall number of partners is an important determinant of HIV risk, it is modified by the way in which partners are selected. It is easy to classify people who have never had sex as having no sexual risk behaviours but, among the sexually active, it is much harder to make a distinction between safe and unsafe behaviour.

The relations between an individual's behaviour and risk of HIV infection have been quantified from case control and prospective studies. When study data are explored for risk factors, the analysis is geared towards finding the most discriminatory measures of risk. These may be identified only after confounding factors have been controlled for in multivariate analysis. The relation between a precise behaviour and HIV infection can be quantified at the individual level but the risk factors which emerge from such analyses are not usually defined in a way which can be commonly measured in a variety of populations. Because they are not generally applicable they cannot be used as indicators. There is a trade off between measuring narrowly defined behaviours with a known relation to HIV infection and more broadly defined behaviours which are common to most populations but have a more diffuse relation to HIV infection.

Many countries now have a series of point estimates for the current set of indicators. It is therefore appropriate to revisit these indicators and assess their performance. We expect to see positive trends in indicators followed by declining trends in HIV incidence and eventually prevalence. This has been seen, but to date this has been clear only in Thailand and Uganda. In Zambia there have been positive changes in key sexual behaviour indicators but it is not certain that these have yet been followed by changes in HIV prevalence. In Tanzania apparently positive changes in the key indicators mask an increase in the fraction of the population that is having risky sex.

Table 1 UNAIDS current indicators

\begin{tabular}{|c|c|c|c|}
\hline Indicator & Name & Denominator & Numerator \\
\hline \multicolumn{4}{|l|}{ All adults } \\
\hline UN1 & $\begin{array}{l}\text { Higher risk sex in the } \\
\text { last year }\end{array}$ & $\begin{array}{l}\text { All who had sex in last } \\
\text { year }\end{array}$ & $\begin{array}{l}\text { People who had sex with non-cohabiting partner } \\
\text { in last year }\end{array}$ \\
\hline UN2 & $\begin{array}{l}\text { Condom use at last higher } \\
\text { risk sex }\end{array}$ & $\begin{array}{l}\text { All who had sex with non- } \\
\text { cohabiting partner in last year }\end{array}$ & $\begin{array}{l}\text { People who used condom at most recent sex with } \\
\text { non-cohabiting partner }\end{array}$ \\
\hline UN3 & $\begin{array}{l}\text { Commercial sex in the } \\
\text { last year }\end{array}$ & All men & Men who had sex with CSW in last year \\
\hline \multicolumn{4}{|c|}{ High risk groups } \\
\hline UN4 & $\begin{array}{l}\text { Condom use at most recent } \\
\text { commercial sex } \\
\text { (client report) }\end{array}$ & $\begin{array}{l}\text { Men who report commercial } \\
\text { sex in the last year }\end{array}$ & $\begin{array}{l}\text { Men who used condom most recent commercial } \\
\text { sex }\end{array}$ \\
\hline UN5 & $\begin{array}{l}\text { Condom use at most recent } \\
\text { commercial sex } \\
\text { (sex worker report) }\end{array}$ & $\begin{array}{l}\text { Sex workers who have had sex } \\
\text { with a client in the last year }\end{array}$ & $\begin{array}{l}\text { Sex workers who used a condom when they had } \\
\text { sex with their most recent client }\end{array}$ \\
\hline UN6 & $\begin{array}{l}\text { Higher risk male-male sex in the } \\
\text { last year }\end{array}$ & $\begin{array}{l}\text { All men in a special } \\
\text { survey of men who have sex } \\
\text { with men }\end{array}$ & $\begin{array}{l}\text { Men who had anal sex with at least one man in } \\
\text { the last } 6 \text { months }\end{array}$ \\
\hline UN7 & $\begin{array}{l}\text { Condom use at most recent anal } \\
\text { sex between men }\end{array}$ & $\begin{array}{l}\text { Men who have had anal sex } \\
\text { with a man in the last } 6 \text { months }\end{array}$ & $\begin{array}{l}\text { Men who used a condom the most recent } \\
\text { occasion they had anal sex with a man }\end{array}$ \\
\hline \multicolumn{4}{|c|}{$\begin{array}{l}\text { Those aged } \\
15-24 \text { years }\end{array}$} \\
\hline UNyl & $\begin{array}{l}\text { Median age at first sex among } \\
\text { young men and women }\end{array}$ & $\begin{array}{l}\text { The age by which } 50 \% \text { of young } \\
\text { people aged } 15-24 \text { say they have } \\
\text { already had sex. }\end{array}$ & \\
\hline UNy2 & $\begin{array}{l}\text { Young people having pre- } \\
\text { marital sex in last year }\end{array}$ & $\begin{array}{l}\text { All young people who have never } \\
\text { had a cohabiting partner }\end{array}$ & $\begin{array}{l}\text { Young people who have never had a cohabiting } \\
\text { partner and who had sex in the last year }\end{array}$ \\
\hline UNy3 & $\begin{array}{l}\text { Young people using a condom } \\
\text { during pre-marital sex }\end{array}$ & $\begin{array}{l}\text { All young sexually active people } \\
\text { who have never had a cohabiting } \\
\text { partner }\end{array}$ & $\begin{array}{l}\text { Those who used a condom at their most recent } \\
\text { sex }\end{array}$ \\
\hline UNy4 & $\begin{array}{l}\text { Young people having multiple } \\
\text { partners in last year }\end{array}$ & All young people & $\begin{array}{l}\text { Young people who report more than one partner } \\
\text { in last year }\end{array}$ \\
\hline UNy5 & $\begin{array}{l}\text { Young people using a condom } \\
\text { at last higher risk sex }\end{array}$ & All young people & $\begin{array}{l}\text { Young people who used condom at the most } \\
\text { recent sex with a non-cohabiting partner in the } \\
\text { last year }\end{array}$ \\
\hline UNy6 & Condom use at first sex & $\begin{array}{l}\text { All young people who } \\
\text { have ever had sex }\end{array}$ & $\begin{array}{l}\text { Young people who used a condom the first time } \\
\text { they had sex }\end{array}$ \\
\hline UNy7 & Age mixing in sexual relationships & $\begin{array}{l}\text { Women aged } 15-19 \text { who had sex } \\
\text { with a man to whom they are not } \\
\text { married in the last } 12 \text { months }\end{array}$ & $\begin{array}{l}\text { Women aged 15-19 who had sex with a man to } \\
\text { whom they are not married and who is } 10 \text { or } \\
\text { more years older (based on their last three } \\
\text { reported partnerships) }\end{array}$ \\
\hline
\end{tabular}


The interpretation of changes in indicators may be contingent on other changes. However, indicators are often presented without supporting information-either the additional data needed for interpretation or the more common adjuncts such as the number of respondents or the source of the data. These latter factors can be as informative for the interpretation of trends. ${ }^{10}$ Policy makers need clear and simple measures, but errors in interpretation may arise without the full picture.

The indicators of sexual behaviour do not necessarily correlate with biological indicators of the epidemic, and in some places trends appear contrary. ${ }^{11}$ The sound epidemiological reasons for this are not apparent from the indicators themselves and many lay people may not be conversant with these subtleties.

This paper aims to review the "effectiveness" of the current indicators: we know that in theory they can be useful, but how are they shaping up in practice?

\section{METHODS}

Three steps were carried out for each aspect of sexual behaviour:

- A list of indicators on the topic was compiled from the UNAIDS/WHO guide for monitoring and evaluation of National AIDS programmes. ${ }^{6}$

- A literature review was carried out to establish how frequently the indicators of sexual risk behaviour had been identified as risk factors for HIV infection among members of the general population.

- The indicator was calculated from good quality, nationally representative data for several countries where two or more estimates were available. The performance of each indicator was assessed against changes in other aspects of sexual behaviour and HIV prevalence.

For the review of the literature Medline and Popline were searched for all papers which mentioned risk factors for HIV infection. Abstracts were reviewed to determine whether the paper covered risk factors for prevalent or incident HIV infection among members of general populations. Suitable papers were obtained, sorted by sexual behaviour topic, and the results were summarised.

In this paper each indicator defined by UNAIDS is referred to by a code rather than the name because many indicators defined by different organisations have the same name but different definitions.

\section{RESULTS}

The literature search produced 15 papers which describe risk factors for HIV infection among general populations in various countries and describe some of the same behaviours as the indicators considered here. ${ }^{11-25}$ There are undoubtedly many more studies of this sort in the grey literature. Six papers are from Uganda, two based on the Masaka cohort ${ }^{14} 22$ and four on the Rakai intervention trial subjects. ${ }^{12} 162021$ The remaining studies are from Ethiopia, Kenya, Rwanda, South Africa, Tanzania, and Zimbabwe.

Although each of the studies used in this paper measured an aspect of sexual behaviour that is also described by an indicator, not all of the researchers chose to measure, or present data on, the behaviour in a way that is comparable with the indicators. Table 2 shows a summary of the results of this review. There is a surprising disparity in the topics reported. The behaviour most commonly described (in 14 of the papers) is the number of partners; condom use is investigated in 10 papers and partner type in nine. The relative infrequency with which some topics are investigated may reflect publication bias resulting from space constraints in journals. The UNAIDS indicator which could be measured most often in the studies described in these papers was the proportion of young people who had more than one partner in the last year (UNy4), which was available in eight out of the 14 papers in which the topic was investigated. This was also the indicator which, when calculated as specified, was most commonly associated with HIV infection (in two studies) and, along with commercial sex (the third UN indicator), most commonly not associated (in three studies).

Type of sexual partner: who is having sex with whom? The choice of sexual partner affects the chance of having sex with somebody who is infected with HIV. It is measured by the first sexual behaviour indicator for adults (UN1): higher risk sex (sex with a non-cohabiting partner) in the last year, and by the second indicator for young people (UNy2): premarital sex in the last year.

These indicators describe the extent to which sex occurs outside cohabiting/marital relationships. Non-cohabiting sexual partners are likely to know less about the infection status and risk behaviour of their partner than those who cohabit. The association between type of partner and HIV infection was investigated in nine studies and a significant association was found in four. In two studies data were collected in such a way that it was possible to measure the first adult sexual behaviour indicator (UN1) but a significant association with HIV was not found in either. The second indicator of young people's sexual behaviour (Uny2) could be calculated from the same data but this was not presented in any of the studies.

Non-cohabiting partners are not a homogenous group. Sex with a non-cohabiting partner would not be expected to emerge as a consistent risk factor because it is not a very specific marker of risk. Many people who have sex with a non-cohabiting partner will have little or no additional risk of HIV infection compared with those who have not done so. It is difficult to define objectively the different types of sexual partnership. Whether a non-cohabiting partner has a high risk of being infected with HIV or a low risk depends on the HIV prevalence and the context of sexual relationships in each country. These distinctions are easier to draw in countries with a concentrated epidemic, where HIV infection is still most common among members of certain groups such as commercial sex workers (CSWs) or injecting drug users. In countries where infection has spread to the general population it is harder to group partners into appropriate categories that are homogeneous with respect to the risk of HIV infection.

Sexual partners can be characterised by the duration of the relationship (for example, more or less than one year), the survey respondent's description (girlfriend, CSW) or by

Table 2 Summary of sexual behaviour risks among members of the general population as described by the UNAIDS indicators and as risk factors in studies

\begin{tabular}{llll}
\hline & & \multicolumn{2}{c}{ Number of studies which: } \\
\cline { 3 - 4 } \cline { 3 - 4 } Topic & $\begin{array}{l}\text { Associated } \\
\text { indicators }\end{array}$ & $\begin{array}{l}\text { Investigated } \\
\text { topic }\end{array}$ & $\begin{array}{l}\text { Found significant } \\
\text { association with } \\
\text { HIV }\end{array}$ \\
\hline Type of sexual partner & UN1 & 9 & 4 \\
Condom use & UN2 \& UNy5 & 10 & 2 \\
Age at first sex & UNy6 & 10 & 2 \\
Number of partners & UNy4 & 7 & 0 \\
Commercial sex & UN3 & 14 & 11 \\
Age mixing in & UNy7 & 3 & 2 \\
sexual relationships & & & 2 \\
\hline
\end{tabular}


the context in which the sex took place (commercial sex, one night stand, rape). While the least subjective characteristic of a relationship between partners is whether they cohabit, it may be too broad a distinction to reflect HIV risk accurately, leading possibly to artificially high estimates of the population at risk. Conversely, if infection is very widespread in the population, even this wide category may not include all those people who are at risk. The indicators describe behaviour in the last 12 months, which is relevant for planning purposes and useful for tracking trends in behaviour, but may not accurately describe the lifetime risk of acquiring HIV infection experienced by members of the population.

Using indicators UN1 or UNy2 to make comparisons between different populations, or to look at trends over time within the same population entails some drawbacks. The group of non-cohabiting partners includes many different types of sexual partner, as shown in figure 1. For men aged 15-24 years, a non-cohabiting partner in Tanzania is likely to be more risky than one in Zimbabwe because they are more likely to be casual partners. The composition of the group of non-cohabiting partners may be a very important determinant of HIV risk but these indicators may fail to capture this.

However, it is difficult to find an alternative to "noncohabiting partner" that would work better because, as figure 1 illustrates, the types of partner described by survey respondents vary considerably. The meanings assigned to these descriptions almost certainly differ between populations. Figure 2 illustrates the average length of young men's sexual relationships, which is not consistently correlated with the type of relationship. The expected monotonic decline in the length of relationship from cohabitation, at one extreme, to sex workers at the other end of the spectrum holds only in Uganda. In Benin, Tanzania, Uganda, and Zimbabwe the description of a relationship is associated with its length, which implies that the terms have specific meaning within each country. But no uniform pattern of association is
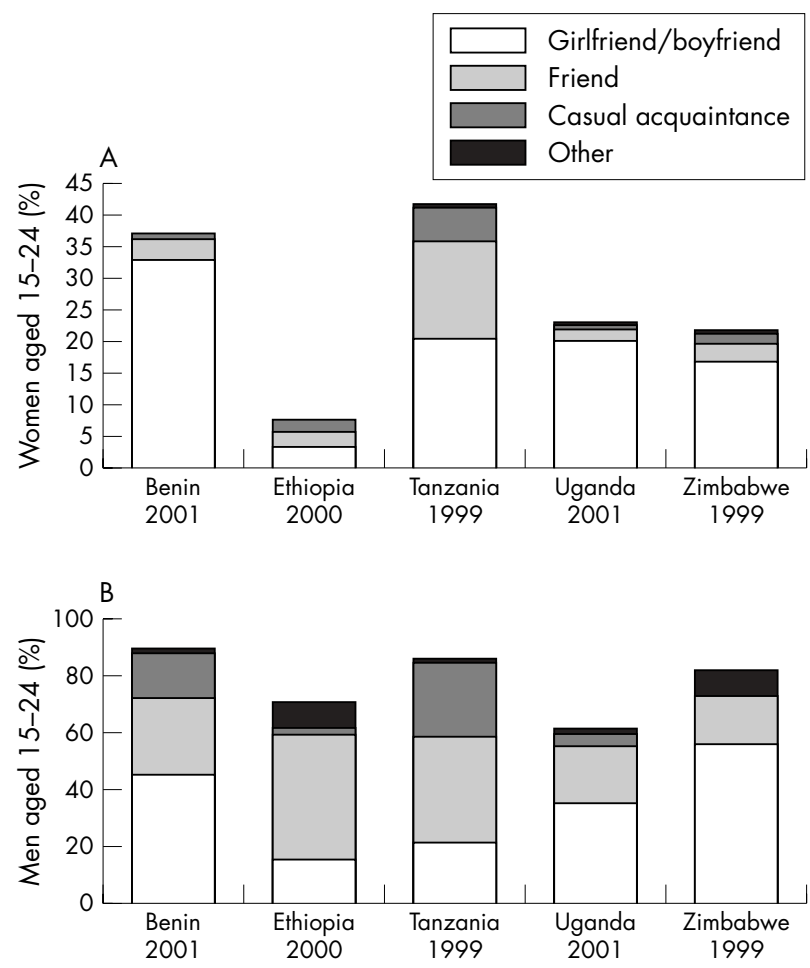

Figure 1 Per cent distribution of all recent non-cohabiting partners reported by young women and men by the way in which the partner was described, by country. Source: Demographic and Health Surveys. ${ }^{26-30}$ evident, implying that the meanings of different types of relationship are context specific.

Figure 3 illustrates that relationships described in the same way by men and women may differ in their longevity. The length of time for which men and women aged 15-24 in Tanzania have been having sex with their girlfriends and boyfriends is very different; men report an average of 48 days (95\% CI 39 to 58 ) whereas women report 428 days (95\% CI 361 to 494). Some of this discrepancy may be explained by age mixing (because the boyfriends of the young women are older men) but this still implies that the men with girlfriends may be more at risk than the women with boyfriends (unless this risk is offset by the additional risk posed to young women by a much older boyfriend). In Zimbabwe the opposite difference is seen in the men's and women's reports. Men aged 15-24 have been having sex with their girlfriends for almost a year on average (334 days, 95\% CI 284 to 383 ) but women of the same age have been having sex with their boyfriends for less than half that time, 126 days on average (95\% CI 107 to 144). Therefore the risk attached to sex with people described as girlfriends and boyfriends can be expected to vary between populations-even without taking HIV prevalence into account.

This implies that great caution is needed when interpreting the results of indicators UN1 and UNy2 (higher risk sex in the last year and premarital sex in the last year). Unless accompanied by more detailed information on the composition of the group of non-cohabiting partners, they are better suited to tracking trends within the same population than to making cross national comparisons.

\section{Condom use}

Condoms are effective in preventing HIV transmission when used properly and consistently. Condom use is measured by five indicators: condom use in most recent higher risk sex act (UN2), condom use in most recent commercial sex act (UN4); condom use in most recent premarital sex act among people aged 15-24 years (UNy2); condom use in most recent higher risk sex act among people aged 15-24 years (UNy5) (different denominator to UN1), and condom use at first sex act (UNy6). Condom use at most recent higher risk sex act among 15-24 year olds only is the indicator chosen as a key UNGASS indicator of sexual behaviour.

The effect of condom use (measured in several different ways) was investigated in 10 of the studies summarised in table 2. In one study there was a significant, positive association between use of a condom and HIV infection. In another study the opposite association was found. In the remainder there was no statistically significant association between condom use and HIV infection. Only one of the 10 studies measured condom use in the same way as an indicator-namely, condom use at first sex (Uny6) —and in that study it was not a significant predictor of HIV infection. ${ }^{13}$ The positive association of condom use with HIV is not unexpected though it is the cause of much confused debate. Condoms may be used in response to a perceived threat of HIV infection. Cross sectional studies cannot elucidate the order in which events occurred. People who know or suspect that they are HIV infected (or that their partner is) may use condoms more often than people who do not consider themselves or their partner likely to be infected. Inconsistent condom use could lead to infection, and in populations where condom use is confined to high risk relationships HIV infection and condom use may then appear to be associated.

Simple measures of use do not capture differences in the consistency and correctness of condom use and both of these factors may vary considerably between populations. The consistency of condom use is important but is not captured by these indicators, which measure use on a specified 


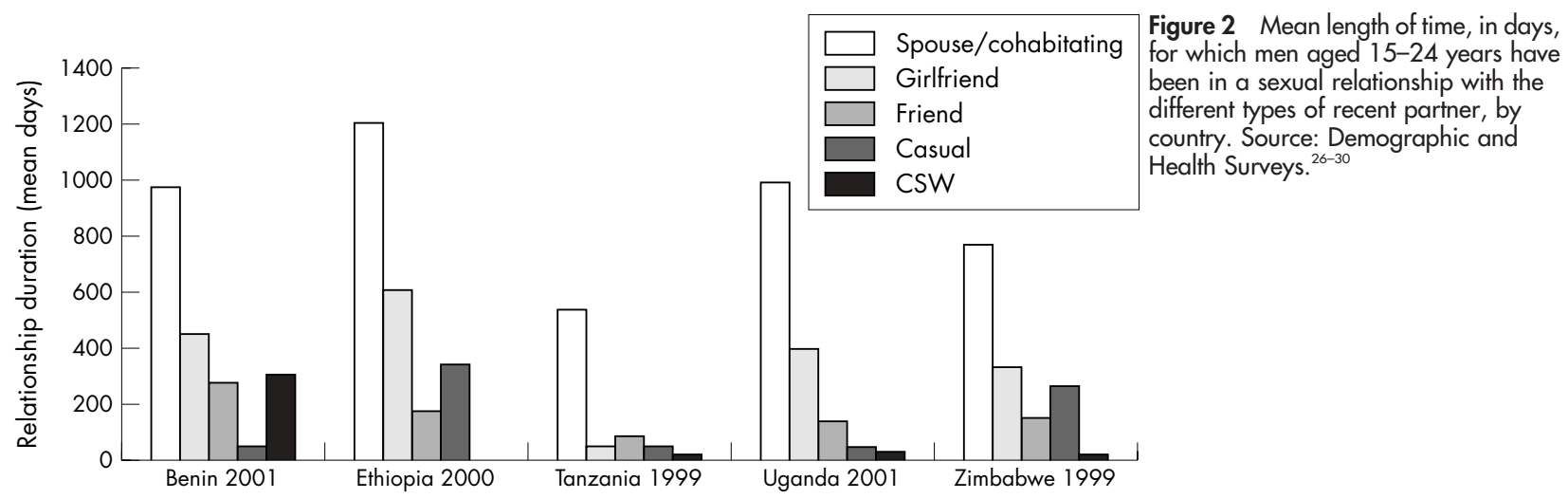

occasion. The terms used to describe the frequency of use are subjective (for example, "sometimes", "occasionally"). This is satisfactory when looking for associations within a population (who can reasonably be expected to attach a similar meaning to the descriptions of frequency) but is inadequate to describe use in different populations. Increases in the percentage of people who report condom use at most recent sex act occur either because people begin to use condoms for the first time, or because inconsistent users start to use them more often.

All five indicators describe use, but the people at risk are those who do not use condoms but who still have sex. Differences in the size of this group, both between populations and over time, will not be reflected by condom use indicators. The proportion of the population that is having sex (with certain types of partner) will also affect the size of this group. Measures which describe the proportion of all people who have risk behaviour and who do not use condoms may be more useful to describe the overall risk profile of a population. This applies to the other indicators of condom use with the exception of use at first sex because this denominator includes everyone who has ever had sex.

Figure 4 shows three population measures of HIV risk behaviour for young men and women in Zambia at four points in time. These measures are restricted to young people aged 15-24 years to show how the condom use measure used as an indicator for monitoring progress towards UNGASS goals compares with other measures. The figure shows the proportion of sexually active young people who had sex with a non-cohabiting partner in the last year (UNI but restricted

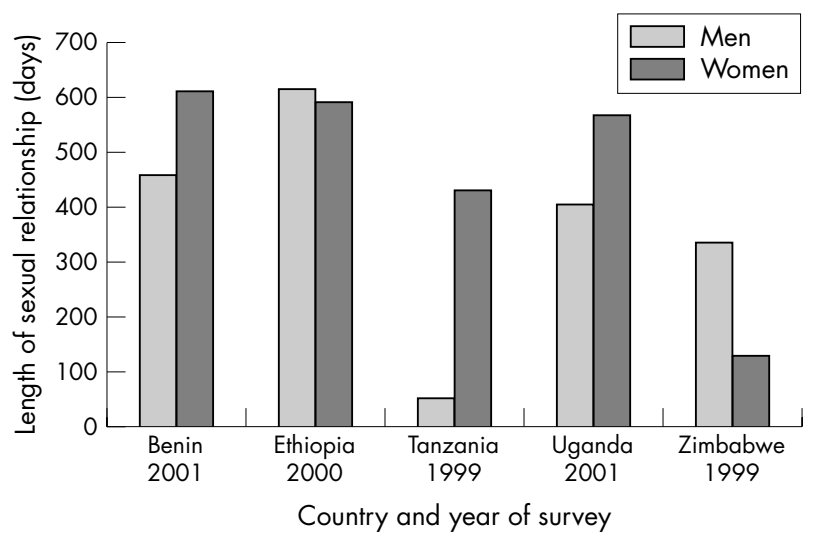

Figure 3 Mean length of time, in days, for which men and women aged 15-24 years have been in a sexual relationship with partners they describe as girlfriends or boyfriends, by country. Source: Demographic and Health Surveys. ${ }^{26-30}$ to young people) and, among those, first-the proportion who used a condom on the most recent occasion (UN2 but restricted to young people, also the UNGASS indicator), and, second-the proportion who did not use a condom on the most recent occasion (unprotected higher risk sex). The size of the unprotected higher risk sex group declines significantly over time for both men and women, but condom use only increases significantly among women. The decline in the proportion of men who are at highest risk is explained by a significant decrease in the proportion of men who had sex with non-cohabiting partners.

\section{Age at first sex}

Young age at first sexual intercourse is thought to increase the risk of acquiring HIV infection. The results from two cities in the UNAIDS four cities study showed that the high prevalence among young women was not fully explained by behavioural factors, ${ }^{31}$ suggesting that immaturity of the genital tract makes them physiologically more susceptible. People who start sex at an early age may be particularly prone to other risky behaviours later in life. ${ }^{32}$ The importance of early sex as a risk factor for HIV infection depends on the context in which the sex occurs. If first sex is at the start of an early marriage, the risk of HIV infection may be lower than if the first (and subsequent) partner(s) are less familiar. In many circumstances, however, very young brides have much older husbands, who may be more likely to have HIV infection than a sexual partner who is of a similar age to the girl. Such considerations again imply that simplistic cross national interpretations of this indicator may be misleading.

Four different methods are used to describe the age at which people start to have sex. Two make use of the current age of the respondent and whether or not they have had sex, the others use retrospective reports of the age at first sex to calculate life table medians. The first indicator for young people (Unyl: median age at first sex) is based on current status data and describes the age by which $50 \%$ of those aged 15-24 years report already having had sex. Age at first sex was investigated and reported in seven of the studies outlined in table 2, but none of these found significant associations with HIV infection. The methods used to summarise this information are sometimes inadequately described but most studies appear to base their measurements on retrospective reports of the age at first sex and not current status (ever had sex).

The best method used to summarise the age at first sex will depend on the setting but the measure must be consistently calculated because each method will give a slightly different estimate. ${ }^{33}$ All estimates tend to be described as median age at first sex and so it is important to state the method used to calculate this measure, and to ensure that the indicator called 
Women: UN1

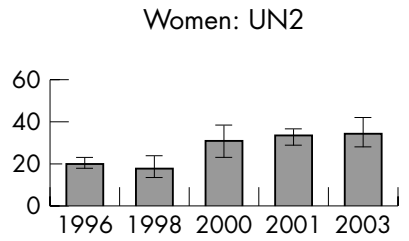

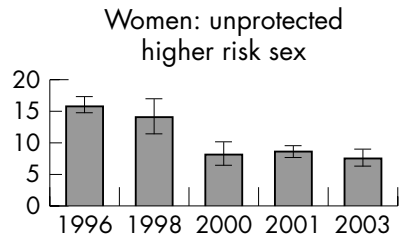

Figure 4 The first and second indicators of adult sexual behaviour and the proportion of the population that had higher risk sex in the last year and did not use a condom the last time, plotted over time, in Zambia.
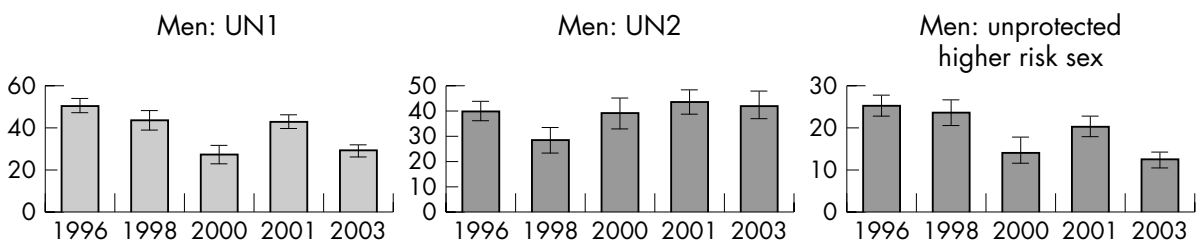

median age at first sex is calculated in the recommended manner.

\section{Number of partners}

The chance of having sex with somebody who is infected with HIV is greater for people who have sex with many partners. This risk depends on the rate at which new partners are acquired and on whether those partners have other partners. The number of partners is measured by the fourth indicator for young people: the proportion of those aged 15-24 years who had sex with more than one person in the last year (UNy4). Number of partners was investigated in 14 of the studies identified and was significantly associated with HIV infection in 11. In eight of these studies it was possible to construct the indicator (young people with more than one partner in the last year, UNy4) from the data collected, but this was actually done in only five studies. The other studies measured the number of non-marital or casual partners, or the number of partners in a lifetime. UNy4 was the indicator that was most often found to be associated with HIV infection (in two studies) but it was also the indicator most commonly not associated (three times). The number of lifetime partners was positively associated with HIV infection in six studies and not associated in two.

Interpretation of any measure of partner numbers suffers from what are assumed to be reporting biases. The numbers of opposite sex partners reported by men and women in surveys are rarely balanced. Men may exaggerate the number of their partners and women may underreport theirs. ${ }^{34}$ Household surveys may miss those few women who have a high number of partners, and who would make the numbers balance were they included. It is very difficult to identify or make allowance for potential problems in the data used to calculate this indicator because it is not possible to tell whether discrepancies in the total number of partners result from misreporting or from a selection bias. Indicators based on this data can still give valuable information on trends in behaviour, providing the extent of the misreporting or selection bias does not change over time.

\section{Commercial sex}

The chance of a sexual partner being infected with HIV is often higher if the partner is a CSW. Commercial sex is notoriously difficult to define. In many cultures it is common to give or receive something for sex, or to trade sex for favours. The extent to which this is organised, with the receiver of gifts or favours having many partners over a short space of time, will affect the HIV risk associated with a partner of this sort. The degree to which those having sex in order to gain something are forced into doing so by economic and social pressures may affect their ability to negotiate safe sex, or to determine with whom and how often they have sex.

The indicator that describes commercial sex is the third adult indicator: the percentage of all men who had sex with a CSW in the last year (UN3). This indicator is limited to populations in which there is a local term equivalent to "prostitution". Condom use with CSWs is described by the fourth and fifth adult indicators. UN4 is based on clients' reports and UN5 on the sex workers' reports.

Commercial sex was assessed as a risk factor for HIV infection in nine of the studies identified in the literature search and was significantly associated in two of those. Three studies reported a measure similar to the indicator (the proportion of men reporting sex with a CSW in the last year) but the denominator in these studies is more usually sexually active men whereas the indicator is based on all men. One study $^{23}$ measured the indicator but did not find an association. Another study in Uganda ${ }^{16}$ found a significant association between HIV incidence and men who reported exchanging money or gifts for sex but the reference period for this behaviour was not reported.

The indicator includes all men in the denominator so it is sensitive to changes in the proportions of men who have ever had sex and who have had sex in the last year. This is especially important in populations where much of men's early sexual experience is with sex workers, because behaviour change may involve first sex at a later age, or less frequent sex before marriage.

In countries with an organised commercial sex "industry" this indicator should provide a good measure of the extent of mixing between men and female CSWs. In countries where transactional sex cannot be easily identified or defined it is harder to interpret this indicator. Condom use with commercial partners was not reported in any of the studies identified in the literature review. This is most probably because of small numbers of men who report this behaviour; in the Demographic and Health Surveys, which usually take a sample of about 2000 men, very few men in some countries report commercial sex, and even fewer report using a condom. This means that the confidence intervals around estimates of these indicators can be very wide (see figs 5 and 6). When tracking trends in indicators that are based on small denominators it is very important to give the confidence intervals.

\section{Age mixing in sexual relationships}

Age mixing in sexual relationships (older men having sex with young women) is thought to be an important factor accelerating the spread of HIV. ${ }^{35}$ The seventh indicator for young people (UNy7) describes the prevalence of sex between 


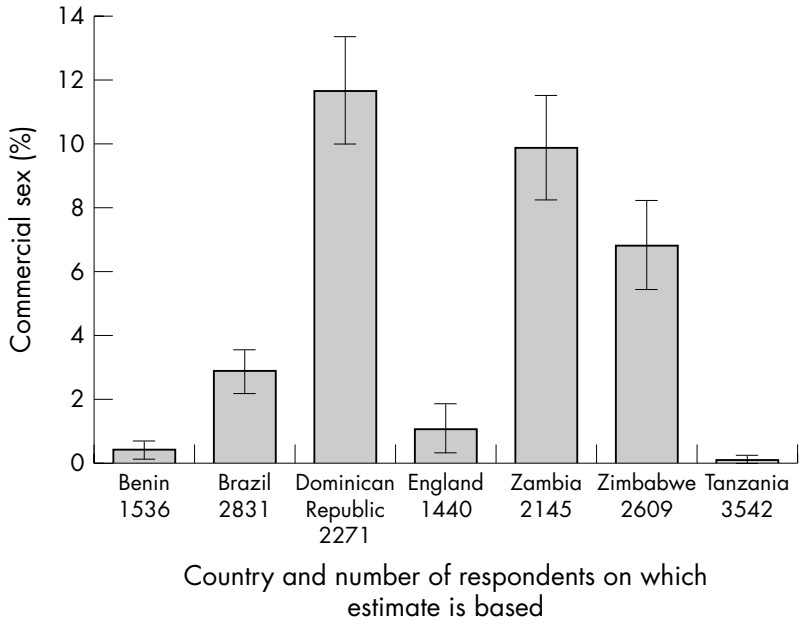

Figure 5 Percentage of all men who had had commercial sex in the last year (indicator UN3), by country.

women aged 15-19 years and non-cohabiting male partners who are 10 or more years older.

In the literature review, sex between partners of different ages was important in two of the three studies which investigated this as a risk factor. The indicator was not used as a measure of this behaviour in any study; one study ${ }^{20}$ assessed sex between women and men 10 years their senior and found that this was a risk factor, which gives good support for the 10 year cut off used in the indicator. However, they found that this did not depend on the type of partner (cohabiting or not), and that this age gap was also important among 20-24 year old women.

Sex between partners of different ages will pose most risk of HIV infection to the younger partner if the older partner has been sexually active for a long time and is therefore more likely to have acquired HIV infection. Marital sex between partners of different ages may actually pose a greater risk because condoms are used less often within marriage than outside it. This indicator measures only the prevalence of non-marital sex between young women and older men.

The HIV risk associated with age mixing depends not only on HIV prevalence but also on the length of time the older men have been sexually active. The risk will be greatest where there is a low age at first sex for both men and women, and partnerships between young women and older men are common. If men's age at first sex is much higher than women's the risk to the women from older male partners will be lessened. In some countries (for example, Mali and Niger) $50 \%$ of women have had sex by age 15 but the median age for men is $20 .{ }^{36}{ }^{37}$ In these circumstances older men may not pose such a great risk compared with countries where the median age at first sex is 16 for both men and women (for example, Kenya and Zambia)..$^{38} 39$

The data on which this indicator is based may be of poor quality for two reasons. The first is that in many places people do not know their age and so it may be difficult for them to estimate the age of their partner. The second is that people are more likely to know the age of their long term partners than those who are more fleeting. If people err towards older or younger ages when they are uncertain of their partners' ages this could lead to a bias.

\section{DISCUSSION AND CONCLUSIONS}

Indicators of sexual behaviour describe the prevalence of various behaviours at population level. Some refer to behaviour in the general population, others describe

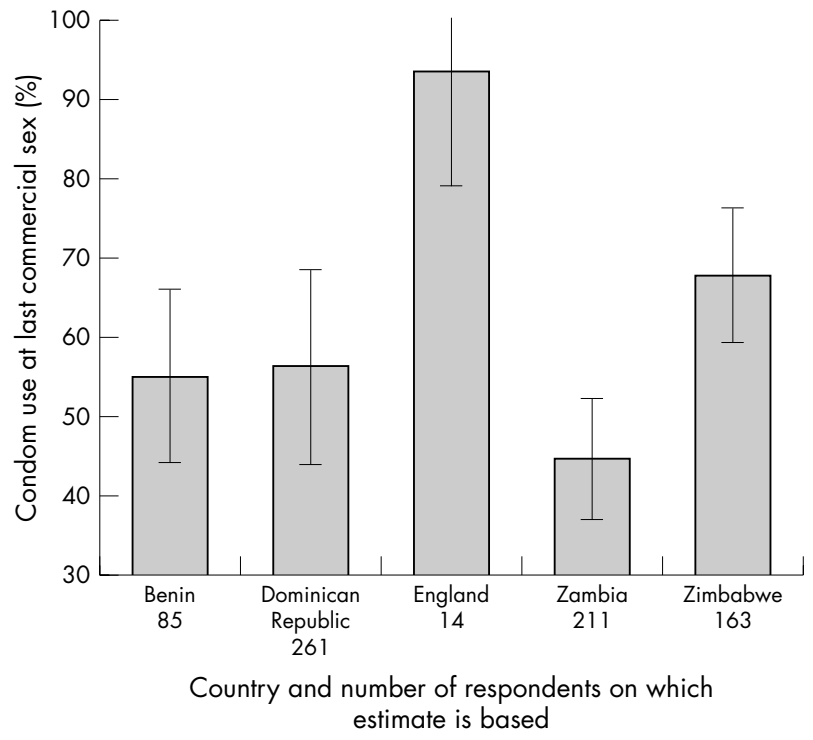

Figure 6 Percentage of men who had had commercial sex in the last year who used a condom on the last occasion (indicator UN4), by country.

behaviour among subgroups. Their purpose is to quantify the sections of the population at risk of HIV infection through their sexual behaviour and to track changes in the size of these risk groups.

The indicators recommended by UNAIDS describe the types of sexual partner, condom use, age at first sex, number of partners, commercial sex, and age mixing between partners. The indicators describe behaviours that are relevant to HIV risk but the relevance of each indicator varies between places. In observational studies, relations have been observed at the individual level between the behaviour described by each indicator and HIV infection, except age at first sex. The behaviours described by the current indicators are amenable to change and this has been observed in practice. ${ }^{10}{ }^{40-45}$

The greatest problem with the current indicators of sexual behaviour is specificity. The nature and context of the relationships within which people have sex vary between populations and between individuals. It is very difficult to find criteria by which relationships can be defined uniformly across cultures and this affects the quality of the first and third adult indicators (UNI and UN3). All the indicators are vulnerable to errors that result from respondents' misunderstandings and these are not always apparent. Knowledge and understanding of human biology and the correct use of condoms can affect how questions about behaviour are interpreted and answered. Differences or limitations in vocabulary can hinder the collection of standard information, especially in populations where sexual matters are not openly discussed. Different meanings may be assigned to the same term in different places. ${ }^{46}$ There may be similar differences within a population, as illustrated by the men's and women's descriptions of girlfriends and boyfriends. ${ }^{47}$

Measuring sexual behaviour is fraught with difficulties. Sex usually takes place in private, and is often secret. Talking about sexual activity is unusual for many people and may be socially unacceptable. Information on sexual behaviour relies on people's reports of their activities and there are no biological markers that can completely replace this. ${ }^{46}$ Social norms may make people reluctant to report some aspects of behaviour, or encourage them to give incorrect information about others. ${ }^{47-50}$ As discussed, there is a problem defining behaviours in a standard way and there is also a problem in 
using such definitions to produce questionnaires which elicit the same information from all respondents. The current indicators cover some of the most measurable aspects of behaviour but may still be inaccurate (for example, age at first sex, number of partners).

All aspects of sexual behaviour are interrelated and so measures of any one aspect cannot be fully understood in isolation. Negative trends or stable levels of one indicator may mask encouraging changes in the population as a whole, as illustrated by the changes in the first two adult indicators estimated for young Zambian men (fig 4). This example also demonstrated that changes in the absolute size of the group with a risk behaviour are as important as proportionate changes. A doubling of the proportion who report condom use at last premarital sex may be of more interest in a population where $30 \%$ of young unmarried people have sex than in one where only $1 \%$ are sexually active before marriage.

Inconsistencies or problems in the measurement of an indicator may affect the results and this could produce misleading conclusions if such problems are not clearly marked. The importance of quality data cannot be overstated. The confidence intervals around indicator estimates are often wide, even when based on large household surveys, and differences in survey methodology can produce very different estimates of the same indicator. ${ }^{48}{ }^{49}$ Comparisons may be valid only if the data on which the estimates are based were collected in the same way.

The indicators currently recommended by UNAIDS do not have much in common with the individual risk factors for HIV infection that have been identified in observational studies. The review of the literature shows that it would be difficult to find a risk factor that was of equal importance in many different African populations. The problem is likely to be greater for intercontinental comparisons. This does not necessarily mean that the current indicators of sexual behaviour do not provide good information about the potential for the spread of HIV infection through a population. However, the current indicators do not provide information that could be used to model the predicted number of new infections in a population. To do that requires more precise information about individual behaviour patterns. Instead the indicators describe the average levels of risk in the population and the trends in these levels which provide insights into the possible future courses of the HIV epidemic. In addition, overall HIV prevalence and how widely infection is distributed among members of the population affect the level of risk of any behaviour.

The precise behaviour and associated levels of risk described by indicators of sexual behaviour are context specific, and so it is unwise to compare the absolute levels of one indicator across different populations. Likewise, comparisons over time are unlikely to be valid unless the survey methodology has remained unchanged. To capture the context in which these behaviours are taking place, the interpretation of the results should take into account a range of indicators rather than considering one indicator in isolation. Some measure of the range of uncertainty around each indicator estimate also aids interpretation of the results, especially for indicators that are based on small numbers or respondents. Indicators must be interpreted in a relative manner: relative to previous levels of that indicator, relative to other indicators, and relative to current HIV prevalence. It is fortuitous if indicators of sexual behaviour can explain the HIV prevalence in a population, but it is not a prerequisite.

There are no competing interests.

\section{REFERENCES}

1 Weller S, Davis K. Condom effectiveness in reducing heterosexual HIV transmission (Cochrane Review). In: The Cochrane Library Issue 4. Chichester, UK: John Wiley \& Sons, Ltd, 2003.

2 World Health Organization (WHO). Technical Consultation on Behalf of the NFPA/UNICEF/WHO/UNAIDS Inter-Agency Task Team on Mother-to-Child Transmission of HIV-1. New data on the prevention of mother-to-child transmission of HIV-1 and their policy implications: conclusions and recommendations. Geneva: WHO, 2000.

3 UNAIDS. Follow-up to the 2001 United Nations General Assembly Special Session on HIV/AIDS: Progress Report on the Global Response to the HIV/ AIDS Epidemic, 2003. Available from http://www.unaids.org/html/pub/ topics/ungass2003/ungassglobal00_en_html.htm (accessed 5 September 2004).

4 Parker RG, Easton D, Klein CH. Structural barriers and facilitators in HIV prevention: a review of international research. Aids 2000;14:S22-S32.

5 Global Programme on AIDS. Evaluation of a National AIDS Programmes: A Methods Package 1. Prevention of HIV Infection. Geneva: WHO, 1994

6 UNAIDS. In: National AIDS Programmes: A Guide to Monitoring and Evaluation, 1st edn. Geneva: UNAIDS, 2000.

7 Family Health International. Behavioural Surveillance Surveys; Guidelines for repeated behavioural surveys in populations at risk of HIV. Arlington: Family Health International, 2000.

8 Webb D, Elliott L. Learning to Live, Monitoring and evaluating HIV/AIDS programmes for young people. London: Save the Children, 2000.

9 UNAIDS. United Nations General Assembly Special Session on HIV/AIDS. Monitoring the Declaration of Commitment on HIV/AIDS. Guidelines on Construction of Core Indicators. Geneva: Joint United Nations Programme on HIV/AIDS (UNAIDS), 2002.

10 Buckner B, Slaymaker E. Sexual behaviour and HIV prevalence in Zambia, 1996-2003. In: Weir S, ed. Workshop on Measurement of Sexual Behaviour in the Era of HIV/AIDS. London, UK: London School of Hygiene and Tropical Medicine, 2003.

11 Auvert B, Buve A, Ferry B, et al. Ecological and individual level analysis of risk factors for HIV infection in four urban populations in sub-Saharan Africa with different levels of HIV infection. AIDS 2001;15(suppl 4):S15-S30.

12 Ahmed S, Lutalo T, Wawer M, et al. HIV incidence and sexually transmitted disease prevalence associated with condom use: a population study in Rakai, Uganda. AIDS 2001;15:2171-9.

13 Auvert B, Ballard R, Campbell C, et al. HIV infection among youth in a South African mining town is associated with herpes simplex virus- 2 seropositivity and sexual behaviour. AIDS 2001;15:885-98.

14 Carpenter LM, Kamali A, Payne M, et al. Independent effects of reported sexually transmitted infections and sexual behavior on HIV-1 prevalence among adult women, men, and teenagers in rural Uganda. J Acquir Immune Defic Syndr 2002;29:174-80.

15 Chao A, Bulterys M, Musanganire F, et al. Risk factors associated with prevalent HIV-1 infection among pregnant women in Rwanda. National University of Rwanda-Johns Hopkins University AIDS Research Team. Int J Epidemiol 1994;23:371-80.

16 Gray RH, Kiwanuka N, Quinn TC, et al. Male circumcision and HIV acquisition and transmission: cohort studies in Rakai, Uganda. Rakai Project Team. AIDS 2000;14:2371-81.

17 Gregson S, Mason PR, Garnett GP, et al. A rural HIV epidemic in Zimbabwe? Findings from a population-based survey. Int J STD AIDS 2001;12:189-96.

18 Hawken MP, Melis RD, Ngombo DT, et al. Opportunity for prevention of HIV and sexually transmitted infections in Kenyan youth: results of a populationbased survey. J Acquir Immune Defic Syndr 2002;31:529-35.

19 Hunter DJ, Maggwa BN, Mati JK, et al. Sexual behavior, sexually transmitted diseases, male circumcision and risk of HIV infection among women in Nairobi, Kenya. AIDS 1994:8:93-9.

20 Kelly RJ, Gray RH, Sewankambo NK, et al. Age differences in sexual partners and risk of HIV-1 infection in rural Uganda. J Acquir Immune Defic Syndr 2003:32:446-51

21 Kiddugavu M, Makumbi F, Wawer MJ, et al. Hormonal contraceptive use and HIV-1 infection in a population-based cohort in Rakai, Uganda. Aids 2003; 17:233-40

22 Malamba SS, Wagner HU, Maude G, et al. Risk factors for HIV-1 infection in adults in a rural Ugandan community: a case-control study. AIDS 1994:8:253-7.

23 Mbizvo MT, Machekano R, McFarland W, et al. HIV seroincidence and correlates of seroconversion in a cohort of male factory workers in Harare, Zimbabwe. AIDS 1996;10:895-901.

24 Mehret M, Mertens TE, Carael M, et al. Baseline for the evaluation of an AIDS programme using prevention indicators: a case study in Ethiopia. Bull World Health Organ 1996;74:509-16.

25 Quigley M, Munguti K, Grosskurth H, et al. Sexual behaviour patterns and other risk factors for HIV infection in rural Tanzania: a case-control study. AIDS 1997; 11:237-48.

26 Central Statistical Authority (Ethiopia) and ORC Macro. Ethiopia Demographic and Health Survey 2000. Addis Ababa, Ethiopia and Calverton. Survey: data and report. Maryland, USA: Central Statistical Authority and ORC Macro, 2001

27 Central Statistical Office (Zimbabwe) and Macro International Inc Zimbabwe Demographic and Health Survey 1999. Survey: data and report. Calverton, Maryland USA: Central Statistical Office and Macro International Inc, 2000.

28 Institut National de la Statistique et de l'Analyse Économique (INSAE) et ORC Macro. Enquête Démographique et de Santé au Bénin 2001. Survey: data 
and report Calverton, Maryland, USA: Institut National de la Statistique et de I'Analyse Économique et ORC Macro, 2002.

29 National Bureau of Statistics (Tanzania) and Macro International Inc. Tanzania Reproductive and Child Health Survey 1999. Survey:data and report.Calverton, Maryland. USA: National Bureau of Statistics and Macro International Inc, 2000.

30 Uganda Bureau of Statistics (UBOS) and ORC Macro. Uganda Demographic and Health Survey 2000-2001. Survey: data and report. Calverton, Maryland, USA: UBOS and ORC Macro, 2001.

31 Glynn JR, Carael M, Auvert B, et al. Why do young women have a much higher prevalence of HIV than young men? A study in Kisumu, Kenya and Ndola, Zambia. AIDS 2001;15(Suppl 4):S51-60.

32 White R, Cleland J, Carael M. Links between premarital sexual behaviour and extramarital intercourse: a multi-site analysis. AIDS 2000;14:2323-31.

33 Zaba BW, Boerma JT, Pisani E, et al. WP-02-51: Estimation of levels and trends in age at first sex from surveys using survival analysis, 2002. Available from: http://www.measureprogram.org/ (accessed 5 September 2004).

34 Nnko S, Boerma J, Urassa M, et al. Secretive females or swaggering males? An assessment of the quality of sexual partnership reporting in rural Tanzania. Soc Sci Med 2004;59:299-310.

35 Anderson RM, May RM. Infectious Diseases of Humans. Dynamics and Control. Oxford: Oxford University Press, 1991.

36 Attama S, Seroussi M, Kourgueni A, et al. Enquéte Démographique et de Santé, Niger 1998. Calverton, Maryland USA: Care International/Niger and Macro International Inc, 1998.

37 Cellule de Planification et du Statistique du Ministère de la Santé (CPS/MS) Direction Nationale de la Statistique et de l'Informatique (DNSI), Macro O. Enquéte Démographique et de Santé au Mali 2001. Calverton, Maryland USA: CPS/MS, DNSI, ORC Macro, 2002.

38 Central Statistical Office Republic of Zambia, Central Board of Health Republic of Zambia, Macro O. Zambia Demographic and Health Survey 2001/2. Survey: data and report. Calverton, Maryland. USA: Central Statistical Office, Central Board of Health and ORC Macro, 2003.

39 National Council for Population, Development (NCPD), Central Bureau of Statistics Kenya (CBS) (Office of the Vice President and Ministry of Planning and National Development), Inc MI. Kenya Demographic and Health Survey 1998. Calverton, Maryland USA: NCPD, CBS, MI, 1999.
40 Asiimwe Okiror G, Opio AA, Musinguzi J, et al Change in sexual behaviour and decline in HIV infection among young pregnant women in urban Uganda. AIDS 1997; 11:1757-63

41 Kamali A, Carpenter LM, Whitworth JAG, et al. Seven-year trends in HIV-1 infection rates, and changes in sexual behaviour, among adults in rural Uganda. AIDS 2000;14:427-34.

42 Kilian AH, Gregson S, Ndyanabangi B, et al. Reductions in risk behaviour provide the most consistent explanation for declining HIV-1 prevalence in Uganda. AIDS 1999;13:391-8.

43 Kilmarx PH, Supawitkul S, Wankrairoj $M$, et al. Explosive spread and effective control of human immunodeficiency virus in northernmost Thailand: the epidemic in Chiang Rai province, 1988-99. AIDS 2000;14:2731-40.

44 Nelson KE, Celentano DD, Eiumtrakol S, et al. Changes in sexual behavior and a decline in HIV infection among young men in Thailand. N Engl J Med 1996;335:297-303.

45 Xu F, Kilmarx PH, Supawitkul S, et al. HIV-1 seroprevalence, risk factors, and preventive behaviors among women in northern Thailand. J Acquir Immune Defic Syndr 2000;25:353-9.

46 Obasi A Plummer M. Evidence from Studies of Young People in Africa. In: Workshop on Measurement of Sexual Behaviour in the Era of HIV/AIDS. London, UK: London School of Hygiene and Tropical Medicine, 2003.

47 Boerma JT, Urassa M. Closed networks for evaluating male-female reporting discrepancy. In: Workshop on Measurement of Sexual Behaviour in the Era of HIV/AIDS. London, UK: London School of Hygiene and Tropical Medicine, 2003.

48 Gregson S. The Performance of Face to Face Interviews and SelfAdministered/More Anonymous Techniques. In: Workshop on Measurement of Sexual Behaviour in the Era of HIV/AIDS. London, UK: London School of Hygiene and Tropical Medicine, 2003.

49 Mensch B, Hewett P. Experience with Computer-Assisted Data Capture Techniques. In: Workshop on Measurement of Sexual Behaviour in the Era of HIV/AIDS. London, UK: London School of Hygiene and Tropical Medicine, 2003

50 Zaba B. Cohort Comparisons-Age at First Sex. In: Workshop on Measurement of Sexual Behaviour in the Era of HIV/AIDS. London, UK: London School of Hygiene and Tropical Medicine, 2003. 